\title{
Longitudinal difference in total electron content over the East Asian region: feature and explanation
}

\author{
Shimei $\mathrm{Yu}^{\mathrm{a}}$, Zuo Xiao ${ }^{\mathrm{a}, \mathrm{b}, *}$, Biqiang Zhao ${ }^{\mathrm{c}}$, Donghe Zhang ${ }^{\mathrm{a}}$, Yongqiang $\mathrm{Hao}^{\mathrm{a}}$ \\ ${ }^{a}$ Institute of Space Physics and Applied Technology, School of Earth and Space Sciences, Peking University, Beijing, China \\ ${ }^{\mathrm{b}}$ State Key Laboratory of Space Weather, National Space Science Center, Chinese Academy of Sciences, Beijing, China \\ ${ }^{\mathrm{c}}$ Institute of Geology and Geophysics, Chinese Academy of Sciences, Beijing, China \\ *Corresponding author. \\ E-mail address: zxiao@pku.edu.cn (Z.Xiao).
}

\section{Abstract}

The mechanism of the longitudinal difference of ionospheric electron density is in general attributed to the thermospheric wind effect modulated by the local geomagnetic declination. Although this mechanism is tested in many case studies, there are other possible factors such as solar activity and so on which still need further investigations. In this paper, TEC data from two Chinese GPS stations located at almost same geographic latitudes but with a wide longitude span $\left(\sim 38^{\circ}\right)$ are used to study the morphological features of longitudinal differences under various geophysical conditions. A parameter $R_{\mathrm{ew}}$ is defined as a normalized measure of the TEC difference between the two stations. All the observed temporal variations of $R_{\mathrm{ew}}$ are analyzed statistically, with the results showing that negative east-west differences (Western TEC > Eastern TEC) in the noontime are pronounced during Day of Year (DoY) 90-270, while nighttime positive differences (Western TEC < Eastern TEC) are around DoY 60-90, and 270-300. All above observed features are examined by the dynamic effect of thermospheric wind using the HWM07 model. The results show that although the zonal wind does play an important role on average, it is not sufficient to explain all the observed features, the longitude dependence of the meridian wind must be considered. Finally, we observed a new feature characterized by the summer nighttime positive value in $R_{\mathrm{ew}}$ which could be related to a Midlatitude Summer Night Anomaly (MSNA) phenomenon. So, it is also concluded that besides the thermospheric wind effect, other mechanisms such as the longitudinal dependence of the plasmaspheric downward flux should also be taken into consideration in explaining the longitudinal differences in the ionosphere.

Keywords: Ionospheric longitudinal difference; TEC; Thermospheric wind effect

\section{Introduction}


Over the last few decades, longitudinal variations in the ionosphere and thermosphere have received extensive attentions in the aeronomy community. In the low latitude and equatorial regions, the well-known wavenumber 4 (WN4) structure (Immel et al., 2006; Hagan et al., 2007) in the to be mainly associated with upward propagation of the nonmigrating atmospheric tides, which modify the electric fields to produce longitudinal variations in the equatorial fountain effect. At midlatitudes, another notable longitude variation in the ionosphere was named the Weddell Sea anomaly (WSA). The WSA is an unusual nighttime enhancement of electron density in summer which was found in the region around the Weddell Sea and Antarctic Peninsula (Penndorf, 1965; Horvath and Essex, 2003; He et al., 2009; Jee et al., 2009). Later, this nighttime electron density enhancement was also observed in the middle latitude of the northern hemisphere named the Midlatitude Summer Nighttime Anomaly (MSNA) or Summer Evening Anomalies (SEAs) (Lin et al., 2009; Thampi et al., 2009; Liu et al., 2010; Burns et al., 2011).

More recently, Zhang et al. (2011) reported a new finding of pronounced longitudinal variations in midlatitude total electron content (TEC) over the continental US manifested as an east-west coast difference with distinct diurnal and seasonal dependencies characterized by a higher east coast TEC in the evening and vice versa in the morning. It has been suggested that these longitudinal variations in ionospheric TEC at midlatitudes are dominated by the longitudinal differences in geomagnetic declination combined with the effect of thermospheric zonal wind, which is analogous to the physical mechanisms proposed for the Weddell Sea Anomaly (WSA) (Luan et al., 2008; Jee et al., 2009; He et al., 2009; Ren et al., 2012). This declination-zonal wind mechanism was further tested by a comprehensive investigation of both electron density longitudinal variations and the nighttime 
thermospheric zonal winds retrieved from the Fabry-Perot interferometer measurements database in the eastern US, and the results successfully show that the observed zonal wind climatology is consistent with the east-west electron density variations in terms of local time, season, and solar cycle dependency (Zhang et al., 2012a). In fact, the east-west electron density difference differs from the MSNA features as follows: (1) The MSNA is primarily an evening enhancement in plasma density, while the newly found longitudinal variation shows a daily variation. (2) The MSNA occurs more evidently in summer; the longitudinal differences occur persistently in all seasons (Zhang et al., 2012b).

East-west longitude differences in the F-region ionospheric electron density not only appear in the North America region, but also exist in other areas with similar geomagnetic configurations. Then it is important to determine the similarities and differences among various regions, which will benefit from the clarification of the dominant factor controlling the regional ionospheric variability. Zhao et al. (2013) examined the climatology of the F2-region peak electron density (NmF2), electron density $(\mathrm{Ne})$ of different altitudes with longitudinal separation in the Far East region based on 3 pairs of ground ionosondes and satellite measurements. The results showed that the east-west differences over the Far East region display clear diurnal variation features, as seen in the US, but they differ in seasonal and solar activity dependence. By analyzing differences of the midlatitude ionospheric TEC in the east and west sides of North America, South America and Oceania based on a ground GPS receiver network, $\mathrm{Xu}$ et al. (2013) revealed that the east-west differences mainly depend on local time and less depend on season and the level of solar activity.

Empirical Orthogonal Functions (EOF) analysis from the contribution of the variance shows that the variation of the east-west difference is a significant ionospheric variability feature, which is 
more prominent than the well-known midlatitude phenomena, winter anomaly. This is instructive for regional ionospheric modeling (Zhang et al., 2013; Chen et al., 2015). Therefore, in this study, we carry out an analysis on the east-west ionospheric difference in the East Asian region based on the TEC data over northern China, which is different from the peak value of F2-region (NmF2) that has been used by Zhao et al. (2013). Furthermore, we will focus on the possible causes of the climatology variation of the east-west difference in northern China to understand the mechanism that could be responsible for the east-west difference seen in ionospheric TEC.

\section{Observation}

The data used for deriving TEC are the raw GPS data in the receiver-independent exchange format with 30s sampling rate. To examine the effects of solar activity, data are taken for high activity years of 2001-2002 and low activity years of 2007-2008 from two Chinese GPS stations located in northern China. These two stations are the east one at Changchun (geographic latitude $43.8^{\circ}$; geographic longitude $125.3^{\circ}$; magnetic inclination $60.1^{\circ}$; magnetic declination $-7.9^{\circ}$ ) and the west one at Urumqi $\left(43.7^{\circ} ; 87.6^{\circ} ; 62.3^{\circ} ; 2.3^{\circ}\right)$, which locates in the same latitudes and are separated by a longitudinal span of about $40^{\circ}$. The data are collected by GPS receivers affiliated with the Crustal Movement Observation Network of China (CMONOC). The type of the receiver at Changchun (Chan) is ASHTECH Z-XII3 (2002), ASHTECH UZ-12 (2007), and the type of the receiver at Urumqi (Urum) is AOA SNR 800 ACT $(2002,2007)$. All the receivers are operated in the semi-codeless tracking mode. The GPS measurements from these receivers are consistent, including the carrier phases and pseudorange measurements of GPS L1 and L2 frequencies.

Dual frequency GPS observation provides a relative time delay of electromagnetic wave at the two frequencies traveling through the dispersive ionosphere. The TEC along the line of sight can be 
derived from this delay (Lanyi and Roth, 1988). Based upon the derived TEC data, the studies of the ionospheric disturbances have been reported frequently (Calais and Minster, 1995; Ho et al., 1996; Saito et al., 1998; Zhang and Xiao, 2005; Huang and Yuan, 2014; Shuai et al., 2014; Jia et al., 2015; Shi et al., 2015). The vertical TEC derivation method in this study was developed by the Peking University. The characteristics of this method are described as follows: Firstly, this method is for calculating the vertical TEC from single GPS site observations. Secondly, the absolute TEC data are calculated by combining the carrier phase and pseudorange measurements of GPS dual-frequency according to the method by Mannucci et al. (1998). Thirdly, the instrumental bias of satellites and receiver are estimated by combing the SCORE (Lunt et al., 1999), and Ma and Maruyama (2003) methods. The ionospheric shell height is assumed to be $400 \mathrm{~km}$, and the cutoff elevation is 25 degrees (e.g. Zhang et al., 2010).

\section{Results}

\subsection{Seasonal variation of diurnal TEC at Changchun and Urumqi}

The vertical TEC at each site is obtained by averaging the vertical TEC data from all GPS satellites with an elevation angle larger than 45 degrees for each observing epoch (30 seconds). Then, the hourly TEC is obtained by averaging the TEC in one hour. Considering possible effects of any sudden disturbances localized at one region could bias one receiver over another (like mid-latitude tongues of ionization observed by Foster et al., (2005)), only the periods of daily mean $\mathrm{Kp}<3$ are used, which removes the effect of geomagnetic activity while ensuring sufficient sample numbers for statistics. Fig. 1a illustrates the diurnal variations of the monthly mean TEC in equinoctial and solstitial months at Changchun(CC) and Urumqi(WM) during the high solar activity year of 2002. From March equinox to December solstics, there are 26, 29, 24 and 22 days of data counted. The 
variation range of $10.7 \mathrm{~cm}$ solar flux index (f107) of the counted days for each month is labeled in each subplot. It can be seen that $\mathrm{f} 107$ varies with considerable magnitude during these months. This to a large extent can explain day-to-day variability of ionospheric TEC as illustrated in the standard deviation $(\sigma)$ plotted as error bars above and below the diurnal average.

For convenience, an index $R_{\mathrm{ew}}$ is defined to represent the east-west difference based on the procedure of Zhang et al. (2011) as $R_{\mathrm{ew}}=\left(\mathrm{TEC}_{\mathrm{CC}}-\mathrm{TEC}_{\mathrm{WM}}\right) /\left(0.5 \times\left(\mathrm{TEC}_{\mathrm{CC}}+\mathrm{TEC}_{\mathrm{WM}}\right)\right)$. The blue empty circle expresses the absolute $\mathrm{TEC}$ difference $\triangle \mathrm{TEC}=\mathrm{TEC}_{\mathrm{CC}}-\mathrm{TEC}_{\mathrm{WM}}$ while the red dot denotes the east-west difference index $R_{\text {ew }}$. The corresponding range of f107 and monthly mean Kp is also labeled in the bracket beside the month. Fig. 1a shows that during the daytime (08:00-18:00 LT) the TEC at WM is higher than that at CC, which is most obvious in June and September, less in March and least in December. Daytime minimum $\triangle$ TEC values are $-7.68,-11.21,-6.55$ and -1.95 TECU respectively, and minimum $R_{\text {ew }}$ values are $-0.24,-0.28,-0.09$ and -0.07 . At night, TEC is obviously higher at CC than at WM in March, while less in the other seasons. Nighttime maximum $\triangle T E C$ values are 6.08, 0.86, 1.89 and 1.78 TECU respectively, and maximum $R_{\text {ew }}$ approache $0.29,0.04$, 0.12 and 0.14 .

Fig. $1 \mathrm{~b}$ presents the diurnal variations of the monthly mean TEC in equinoctial and solstitial months at CC and WM during the low solar activity year of 2007. For each month, f107 varies with a much smaller magnitude than during 2002. From March equinox to December solstice the day numbers with daily mean $\mathrm{Kp}<3$ are $28,29,27$ and 28 . The overall geomagnetic activity is quiet as most of the daily mean $\mathrm{Kp}$ is around 1.0. It is shown from the figure that during the daytime TEC at $\mathrm{WM}$ is higher than that at $\mathrm{CC}$, this phenomenon is also obvious in June and September, but the magnitude is much smaller compared to the year with high solar activity. Daytime minimum $\Delta \mathrm{TEC}$ 
values are -1.87 and -2.34 TECU, and minimum $R_{\text {ew }}$ approache -0.11 and -0.18 . There is no east-west difference in March and December during the daytime. At night, TEC is also higher at CC than at WM. This is most evident in March and June, with nighttime maximum $\triangle$ TEC being 1.89 and 2.53 TECU, and maximum $R_{\mathrm{ew}}$ approaching 0.18 and 0.25 . Comparison between the results of year 2002 and 2007 indicates that the daytime magnitude of $R_{\mathrm{ew}}$ has a clear positive correlation with solar activity, while the nighttime $R_{\mathrm{ew}}$ in March and September does not show such a clear dependence. Also in December 2007, $R_{\mathrm{ew}}$ shows a totally negative value during the entire nighttime with the minimum approaching -0.2, which indicates that the nighttime TEC at WM is higher than that at CC.

\subsection{Local time and Day of Year (DoY) variation in $\boldsymbol{R}_{\mathrm{ew}}$}

To understand more details in how $R_{\text {ew }}$ changes with local time, season and solar activity, we calculate $R_{\mathrm{ew}}$ for every single day for the year of 2001, 2002, 2007 and 2008. Since $R_{\mathrm{ew}}$ has large day-to-day variability and data gaps occur ( 40 days a year), data smoothing has been employed to suppress the fluctuations and discontinuity. First, we perform a 31-day smooth mean for $R_{\text {ew }}$ of each local time independently and then for each day a 3-hour smooth mean is employed. After the processes above, the climatology characteristics of $R_{\mathrm{ew}}$ are well illustrated as shown in Figs. 2a and 2b for periods of 2001-2002, 2007-2008. The upper panel of Fig. 2a shows that the negative $R_{\text {ew }}$ in 2001 is most significant ( - -0.45) during DoY 120-150 and lasts for nearly the entire daytime. Another daytime minimum appears around DoY 210 but is much smaller and appears only around 09:00-12:00 LT. The negative $R_{\text {ew }}$ in 2002 is relatively pronounced around DoY 170-190 and 240-270, which shows a different pattern from that in 2001. Furthermore, we have noticed that in the nighttime during the periods of DoY 0-30 and 330-360 $R_{\text {ew }}$ show a notable negative value, which indicates that the west TEC is higher than the east one during the winter nighttime for the high solar 
activity year.

The positive $R_{\mathrm{ew}}$ in 2001 mainly appears around DoY 80-110 and 270-300 during the nighttime at 21:00-06:00 LT. This equinoctial pattern also occurs in year 2002 but less significantly. Furthermore, there is another maximum around DoY 30, which can also be identified in the year 2002. During summer seasons of DoY $150-240$ at night, $R_{\text {ew }}$ has a small positive value of 0.1 compared to the equinoctial value for both 2001 and 2002.

As shown in Fig. 2b, for the low solar activity years of 2007 and 2008, the distribution patterns of both the positive and negative $R_{\text {ew }}$ are largely resemble that shown in the years of 2001 and 2002, but the magnitude is smaller. One different feature is that the nighttime positive $R_{\text {ew }}$ during the period of DoY 120-210 is larger for 2007 and comparable for 2008 to the equinoctial value of $R_{\text {ew }}$. Furthermore, the winter nighttime negative value for the low solar activity year is also seen in Fig. $1 b$.

\section{Possible explanation for the climatology feature of $\boldsymbol{R}_{\mathrm{ew}}$}

It has been reported that the midlatitude east-west difference in NmF2 over East Asia is mainly due to the difference of local magnetic declination that leads to the plasma drifting upward and downward across the zero declination longitude under the effect of thermospheric zonal wind (Zhang et al., 2012; Zhao et al., 2013). The upward/downward field aligned drifts move the ions to higher/lower altitudes where their recombination rates are smaller/larger and thus increase/decrease the F-region plasma density (Rishbeth, 1998). This mechanism well captures the diurnal variation of the reverse $R_{\text {ew }}$ observed during the daytime and nighttime in the month of June as an example (Zhao et al., 2013). However, the LT and DoY distribution in $R_{\mathrm{ew}}$ for a whole year has not yet been understood. Here we investigate whether the zonal wind effect can explain the yearly and seasonal 
variation in $R_{\text {ew }}$ described in the above section or other additional contributing factors should be introduced.

It has been pointed out that the altitude distribution of the pronounced daytime (12:00 LT) negative $R_{\text {ew }}$ mainly concentrates at $270-450 \mathrm{~km}$ and nighttime (20:00 LT) positive $R_{\text {ew }}$ at 270-400 $\mathrm{km}$ (Zhao et al., 2013). We therefore use the geomagnetic field and neutral wind parameters at $300 \mathrm{~km}$ over the year of 2002 to calculate the ion drift caused by neutral winds. Here we define Vdz (positive for upward drift), the vertical component of the field aligned ion drift caused by the thermospheric zonal wind. It is obtained by $-U_{e} \sin D \cos I \sin I$, where $D$ and $I$ are the geomagnetic declination and inclination derived from the 11th generation of International Geomagnetic Reference Field (IGRF) and $U_{e}$ is the zonal wind (positive for eastward). Thus the difference in Vdz between $\mathrm{CC}$ and $\mathrm{WM}$ can be expressed as $\Delta \mathrm{Vdz}$ defined as $\mathrm{Vdz} \mathrm{c}_{\mathrm{cc}}-\mathrm{Vdz}_{\mathrm{wm}}$. The vertical component of the field aligned ion drift caused by the thermospheric meridional wind, $\mathrm{Vdm}$, is defined by $-U_{n} \cos D \cos I \sin I$ with $U_{n}$ the meridional wind (positive for northward). Hence, the difference in Vdm between CC and $\mathrm{WM}$ can be expressed as $\Delta \mathrm{Vdm}$. The combined effect is $\Delta \mathrm{Vd}$ defined as $\Delta \mathrm{Vdz}+\Delta \mathrm{Vdm}$.

To obtain $U_{e}$, the Horizontal Wind Model (HWM), a well-known empirical global wind model of the upper thermosphere, is used. HWM has undergone several upgrades incorporating Atmospheric Explorer (AE-E), Dynamics Explorer (DE2), Wind Imaging Interferometer (WINDII) satellite observation, ground-based FPI, ISR observation, MF Radar/Meteor Radar, radiosonde data, and gradient wind derived from International Reference Atmosphere (CIRA-86) tabulations and becomes the present version HWM07 (Hedin et al., 1988, 1991, 1996; Drob et al., 2008). HWM has been extensively utilized in atmosphere and space sciences researches for explaining the climatology phenomena or space weather prediction as it provides a balance between pre-computed pattern and a 
full coupled theoretical calculation (Drob et al., 2008). Here, we use the U.S. Naval Research Laboratory HWM routine to calculate the meridional and zonal components of the wind under magnetically quiet conditions.

Fig. 3 from top to bottom illustrates the LT and DoY variation of $\Delta \mathrm{Vdz}, \Delta \mathrm{Vdm}$, and their combined effect with thermospheric wind derived from HWM07. It is shown that large negative $\Delta \mathrm{Vdz}, \leq-6 \mathrm{~m} / \mathrm{s}$, occurs during DoY 60-270 and 06:00-10:00 LT. This pattern matches well with the distribution of a large negative value of $R_{\text {ew }}$ appearing in Figs. 2a and 2b in the years of 2001-2002 and 2007-2008. The minimum $R_{\text {ew }}$ lags the minimum $\Delta \mathrm{Vdz}$ by about 1-2 hours which mainly appears during 08:00-12:00 LT. The delay is due to the time that is needed for the ionosphere to drift for several tens of kilometers and the recombination process due to the elevation of the F-layer to take effect. However, the pattern fails to reproduce the minimum $R_{\text {ew }}$ during DoY 120-150 and 240-270. The pattern predicts $\geq 4 \mathrm{~m} / \mathrm{s}$ and $\geq 2 \mathrm{~m} / \mathrm{s}$ nighttime enhancement in $\Delta \mathrm{Vdz}$ at DoY $240-365$ and 0-90 during 18:00-24:00 LT and 00:00-03:00 LT. The distribution of nighttime positive $\Delta \mathrm{Vdz}$ shows equinoctial asymmetry represented by large values of $\geq 6 \mathrm{~m} / \mathrm{s}$ for 19:00-23:00 LT and $\geq 4 \mathrm{~m} / \mathrm{s}$ for 00:00-02:00 LT appearing in DoY 250-300. The distribution of nighttime positive $\Delta \mathrm{Vdz}$ generally agrees with the distribution of nighttime positive $R_{\mathrm{ew}}(\geq 0.1)$ appearing in DoY 30-120 and DoY 240-330. However, the nighttime positive $R_{\text {ew }}$ during some days and local time has a larger value than that in the other periods. This is illustrated in Fig 2a around DoY 80-100 and DoY 270-300 during 00:00-06:00 LT for 2001 and 2002. Similar feature appears during 2007 and 2008 although the nighttime enhancement of $R_{\mathrm{ew}}$ is not as large as that for the high solar activity year shown in Fig 2b. This feature also exists in the NmF2 changes as illustrated in Fig. 3 of Zhao et al. (2013). This local time enhancement pattern in $R_{\mathrm{ew}}$ is well reproduced in the distribution of $\Delta \mathrm{Vdm}$ showing larger 
positive values of $5 \mathrm{~m} / \mathrm{s}$ and $10 \mathrm{~m} / \mathrm{s}$ around DoY 90 and DoY 270-300 during 00:00-03:00 LT as seen in the second panel of Fig. 3. The superimposed $\Delta \mathrm{Vdz}$ and $\Delta \mathrm{Vdm}$ effect $\Delta \mathrm{Vd}$ shown in the bottom panel of Fig. 3 maximizes the summer daytime negative value and equinoctial nighttime positive value, which captures the seasonal variation of positive $R_{\text {ew }}$ fairly well as illustrated in Figs. 2a and can be from $5 \mathrm{~m} / \mathrm{s}$ to $15 \mathrm{~m} / \mathrm{s}$.

So far we have compared the distribution of $R_{\mathrm{ew}}$ in TEC with the difference of the vertical 
252 Fig. 2, we can find a reasonable quantitative relationship between the distribution of $R_{\text {ew }}$ in TEC and 253 the difference of the vertical component of the field aligned ion drift caused by the thermospheric 254 wind. For example $\Delta \mathrm{Vd}$ is $-20 \mathrm{~m} / \mathrm{s}$ during DoY $150 \sim 210$ while $R_{\text {ew }}$ is $\sim-0.25$ in 2002 , and $10 \mathrm{~m} / \mathrm{s}$ 255 during DoY 270 300 while $R_{\text {ew }}$ is $\sim 0.18$ in 2001.

From the above results, we can see that the climatology features of $R_{\mathrm{ew}}$ are well described by the thermospheric wind from HWM07. Thus, there are two main potential causes of the excess or reduced TEC at one station vs. the other. One is the variation in thermospheric neutral winds due to climatological effects that can force vertical motion and therefore a change in recombination rate resulting in a change in TEC. The other is the change in the magnetic field configuration for the two stations due to the tilted dipole, which affects the vertical speed. The analysis in Fig. 3 includes both of the causes, the thermospheric wind variation and the different magnetic field configuration. However, both zonal and meridional effects are considered in the above analysis, we are still interested in distinguishing the individual effects of these two components of the thermospheric wind. still resembles that of Fig. 3. However, the nighttime equinoctial enhancement is significantly reduced as illustrated in both the distributions of $\Delta \mathrm{Vdm}$ and $\Delta \mathrm{Vd}$ shown in the middle and bottom 
274 panels of Fig. 4. Furthermore, the magnitudes of both the positive and negative values of $\Delta \mathrm{Vd}$ are 275 largely reduced compared with those shown in the bottom panel of Fig. 3. This indicates that when modeling the $R_{\mathrm{ew}}$ in the Asia sector, both zonal and meridian components play an important role and 277 an accurate local wind model must be used.

The above results also show that the thermospheric wind mechanism alone can not entirely explain the summer nighttime enhancement in $R_{\mathrm{ew}}$ shown in the year of 2007 around DoY 150-180.

The summer nighttime positive value in $R_{\mathrm{ew}}$ is due to the WSA or MSNA appearing at $\sim 135^{\circ} \mathrm{E}$ geographic longitude at 18:00-24:00 LT over the Northeast Asia (Lin et al., 2010). Chen et al. (2011) theoretically investigated the formation of the MSNA, and pointed out that although the equatorward neutral wind is the critical driver for the formation of WSA, the plasmaspheric downward flux provides the plasma source after 22:00 LT which maintains the intensity of the WSA density structure. Thus the east-west difference here could also be related to the longitude difference in the plasmaspheric downward flux. It is shown that the summer nighttime positive value in $R_{\mathrm{ew}}$ is more could produce stronger vertical plasma drift and then result in higher electron density in the ionosphere at midlatitudes. Finally, we noticed that the winter nighttime negative $R_{\mathrm{ew}}$ distributed 
around DoY 330-30 which is evident for the year 2001, 2007 and weak in 2002 and 2008 (also appear in $\mathrm{NmF} 2$ ). This feature cannot be fully explained by the current distribution of $\Delta \mathrm{Vdz}$ and $298 \Delta \mathrm{Vdm}$.

\section{Summary}

The present study focuses on the longitudinal east-west differences in ionospheric TEC observed over northern China, specifically the climatology of the east-west difference index, $R_{\text {ew }}$. The patterns of east-west asymmetry in TEC basically resemble those of NmF2 reported before (Zhao et al., 2013), based on the comprehensive analysis of 4 years of GPS data. The results indicate that the negative east-west differences (Western TEC > Eastern TEC) at noon are pronounced during DoY 90-270, while the nighttime positive differences (Western TEC < Eastern TEC) are around DoY 60-90, 270-300. The observed climatological variations of $R_{\mathrm{ew}}$ are examined by the dynamic effects of the thermospheric winds using HWM07. The results show that thermospheric zonal winds alone cannot explain the DoY variations of all the $R_{\mathrm{ew}}$ features. The longitude dependence of the meridional winds should also be taken into account, especially in explaining the nighttime equinoctial enhancement of $R_{\text {ew }}$. Besides, HWM07 cannot describe the daytime pronounced negative $R_{\text {ew }}$ around DoY 120-150 and 240-270 and winter nighttime negative $R_{\text {ew }}$. This is understood that HWM has several limitations, in which the most evident one is the sparse ground-based data used. Most FPI and ISR observations are relatively concentrated in American and European longitudes while extremely limited at other longitudes (Meriwether et al., 2006). Recent local wind model from FPI wind measurement over northern China has shown that there exists considerable difference in the nighttime climatology of the thermospheric wind between the local observations and HWM (Yao 
et al., 2015). The summer nighttime positive $R_{\mathrm{ew}}$ couldpossibly be explained by other mechanisms, such as the longitude dependence of the plasmaspheric downward flux. At the same time some new issues arise, for example, the winter nighttime negative value appearing in $R_{\mathrm{ew}}$, the day-to-day variability and magnetic storm effect between WM and CC, all of which needs a detailed study in the future.

\section{Acknowledgments}

This work was supported by the Chinese Academy of Sciences (KZZD-EW-01), the National Science Foundation of China (41131066, 41574144, 41274155, 41174138, 41174065, 41321003) and the National Important Basic Research Project (2011CB811405, 2012CB825604). Part of the data are from the Meridian Project. The GPS TEC data are based on IGS. The authors also acknowledge the reviewers for their careful evaluations and helpful suggestions in improving the quality of this paper.

\section{References}

Burns, A.G., Solomon, S.C., Wang, W., Richmond, A.D., Jee, G., Lin, C.H., Rocken, C., Kuo, Y.H., 2011. The summer evening anomaly and conjugate effects. J. Geophys. Res. 116, A01311, doi:10.1029/2010JA015648.

Calais, E., Minster, J. B., 1995. GPS detection of ionospheric perturbations following the January 17, 1994, Northridge earthquake. Geophys. Res. Lett., 22, 1045-1048, doi:10.1029/95GL00168.

Chen, C.H., Huba, J.D., Saito, A., Lin, C.H., Liu, J.Y., 2011. Theoretical study of the ionospheric Weddell Sea Anomaly using SAMI2. J. Geophys. Res. 116, A04305

Chen, C.H., Saito, A., Lin, C.H., Liu, J.Y., 2012. Long-term variations of the nighttime electron density enhancement during the ionospheric midlatitude summer. J. Geophys. Res. 117, A07313

Chen, Z., Zhang, S.R., Coster, A.J., Fang, G., 2015. EOF analysis and modeling of GPS TEC climatology over North America. J. Geophys. Res. 120, doi:10.1002/2014JA020837.

David, M., Sojka, J. J., and Schunk, R. W., 2016. How uncertainty in the neutral wind limits the accuracy of ionospheric modeling and forecasting. J. Geophys. Res. Space Physics, 121, 519-528, doi:10.1002/2015JA021544.

Drob, D.P., Emmert, J.T., Crowley, G., et al., 2008. An empirical model of the Earth's horizontal wind fields: HWM07. J. Geophys. Res. 113, A12304, doi:10.1029/2008JA013668. 
Foster, J.C., Coster, A.J., Erickson, P.J., et al., (2005). Multiradar observations of the polar tongue of ionization, J. Geophys. Res., 110, A09S31, doi:10.1029/2004JA010928.

Hagan, M.E., Maute, A., Roble, R.G., Richmond, A.D., Immel, T.J., England, S. L., 2007. Connections between deep tropical clouds and Earth's ionosphere. Geophys. Res. Lett. 34, L20109, doi:10.1029/2007GL030142.

He, M., Liu, L., Wan, W., Ning, B., Zhao, B., Wen, J., Yue, X., Le, H., 2009. A study of the Weddell Sea Anomaly observed by FORMOSAT-3/COSMIC. J. Geophys. Res., 114, A12309, doi:10.1029/2009JA014175.

Hedin, A.E., Biondi, M.A., Burnside, R.G., Hernandez, G., Johnson, R.M., Killeen, T.L., Virdi, T.S., 1991. Revised global model of thermosphere winds using satellite and ground-based observations. J. Geophys. Res. 96(A5), 7657-7688.

Hedin, A.E., Fleming, E.L., Manson, A.H., Schmidlin, F.J., Avery, S.K., Clark, R.R., Vincent, R.A., 1996. Empirical wind model for the upper, middle and lower atmosphere. J. Atmos. Terr. Phys, 58(13), 1421-1447.

Hedin, A.E., Spencer, N.W., Killeen, T.L., 1988. Empirical global model of upper thermosphere winds based on Atmosphere and Dynamics Explorer satellite data. J. Geophys. Res. 93, 9959-9978, doi:10.1029/JA093iA09p09959.

Ho, C.M., Mannucci A.J., Lindqwister U.J., Pi X., Tsurutani B. T., 1996. Global ionospheric perturbations monitored by the worldwide GPS network. Geophys. Res. Lett., 23, 3219-3222, doi:10.1029/ 96GL02763.

Horvath, I., Essex, E.A., 2003. Vertical E.B drift velocity variations and associated low-latitude ionospheric irregularities investigated with the TOPEX and GPS satellite data. Ann. Geophys. 21, 1017-1030.

Huang, Z., Yuan, H., 2014. Research on regional ionospheric TEC modeling using RBF neural network. Sci. China Tech. Sci., 57(6): 1198-1205. doi:10.1007/s11431-014-5550-0.

Immel, T.J., Sagawa, E., England, S.L., Henderson, S.B., Hagan, M.E., Mende, S.B., Frey, H.U., Swenson, C.M., Paxton, L.J., 2006. Control of equatorial ionospheric morphology by atmospheric tides. Geophys. Res. Lett. 33, L15108, doi:10.1029/2006GL026161.

Jee, G., Burns, A.G., Kim, Y.H., Wang, W., 2009. Seasonal and solar activity variations of the Weddell Sea Anomaly observed in the TOPEX total electron content measurements. J. Geophys. Res. 114, A04307, doi:10.1029/2008JA013801.

Jia, Y., Zhang, S.D., Yi, F., Huang, C.M., Huang, K.M., Gan, Q., Gong, Y., 2015. Observations of gravity wave activity during stratospheric sudden warmings in the Northern Hemisphere. Sci. China Tech. Sci., 58(6): 951-960. doi:10.1007/s11431-015-5806-3. 
Kawamura, S., Otsuka, Y., Zhang, S.R., Fukao, S., Oliver, W.L., 2000. A climatology of middle and upper atmosphere radar observations of thermospheric winds. J. Geophys. Res. 105(A6), 12777-12788.

Lanyi, G.E., Roth, T., 1988. A comparison of mapped and measured total ionospheric electron content using global positioning system and beacon satellite observations. Radio Sci. 23, 483-492, doi:10.1029/RS023i004p00483.

Lin, C.H., Liu, C.H., Liu, J.Y., Chen, C.H., Burns, A.G., Wang, W., 2010. Midlatitude summer nighttime anomaly of the ionospheric electron density observed by FORMOSAT-3/COSMIC. J. Geophys. Res. 115, A03308, doi:10.1029/2009JA014084.

Lin, C.H., Liu, J.Y., Cheng, C.Z., Chen, C.H., Liu, C.H., Wang, W., Burns, A.G., Lei, J., 2009. Three-dimensional ionospheric electron density structure of the Weddell Sea Anomaly. J. Geophys. Res. 114, A02312, doi:10.1029/2008JA013455.

Liu, H., Thampi, S.V., Yamamoto, M., 2010. Phase reversal of the diurnal cycle in the mid-latitude ionosphere. J. Geophys. Res. 115, A01305, doi:10.1029/2009JA014689.

Luan, X., Wang, W., Burns, A., Solomon, S.C., Lei J., 2008. Midlatitude nighttime enhancement in $\mathrm{F}$ region electron density from global COSMIC measurements under solar minimum winter condition. J. Geophys. Res. 113, A09319, doi:10.1029/2008JA013063.

Lunt, N., Kersley, L., Bishop, G.J., Mazzella, A.J., Bailey, G.J., 1999. The effect of the protonosphere on the estimation of GPS total electron content: Validation using model simulations. Radio Science, 34(5): 1261-1271.

Ma, G., Maruyama, T., 2003. Derivation of TEC and estimation of instrumental biases from GEONET in Japan, Annales Geophysicae. Copernicus GmbH, 21(10): 2083-2093.

Mannucci, A.J., Wilson, B.D., Yuan, D.N., Ho, C.H., Lindqwister, U.J., Runge T.F., 1998. A global mapping technique for GPS-derived ionospheric total electron content measurements. Radio Science, 33(3): 565-582.

Meriwether, J.W., 2006. Studies of thermospheric dynamics with a Fabry-Perot interferometer network: A review. J. Atmos. Terr. Phys. 68, 1576-1589

Penndorf, R., 1965. The average ionospheric conditions over the Antarctic, in Geomagnetism and Aeronomy, Antarct. Res. Ser., vol. 4, Waynick, A.H., ed. AGU, Washington, D. C, 1-45.

Ren, Z., Wan, W., Liu, L., Le, H., He M., 2012. Simulated midlatitude summer nighttime anomaly in realistic geomagnetic fields. J. Geophys. Res. 117, A03323, doi:10.1029/2011JA017010.

Rishbeth, H., 1998. How the thermospheric circulation affects the ionospheric F2-layer. J. Atmos. Sol. Terr. Phys. 60, 1385-1402, doi:10.1016/S1364-6826(98)00062-5. 
Saito, A., Fukao, S., Miyazaki, S., 1998. High resolution mapping of TEC perturbations with the GSI GPS network over Japan. Geophys. Res. Lett. 25, 3079-3082, doi:10.1029/98GL52361.

Shi, H., Zhang, D.H., Liu, Y.M., Hao, Y.Q., 2015. Analysis of the ionospheric variability based on wavelet decomposition. Sci. China Tech. Sci., 58(1): 174-180. doi:10.1007/s11431-014-5709-8.

Shuai, J., Zhang, S.D., Huang, C.M., Yi, F., Huang, K.M., Gan, Q., Gong, Y., 2014. Climatology of global gravity wave activity and dissipation revealed by SABER/TIMED temperature observations. Sci. China Tech. Sci., 57(5): 998-1009.doi:10.1007/s11431-014-5527-z.

Sojka, J. J., Jensen, J., David, M., Schunk, R. W., Woods, T., Eparvier, F., 2013. Modeling the ionospheric E and F1 regions: Using SDO-EVE observations as the solar irradiance driver. J. Geophys. Res. Space Physics, 118, 5379-5391, doi:10.1002/jgra.50480.

Thampi, S., Lin, C.H., Liu, H., Yamamoto, M., 2009. First tomographic observations of the mid-latitudes summer night anomaly (MSNA) over Japan. J. Geophys. Res. 114, A10318, doi:10.1029/2009JA014439.

Xu, J.S., Li, X.J., Liu, Y.W., Jing M., 2014. TEC differences for the mid-latitude ionosphere in both sides of the longitudes with zero declination. Adv. Space Res. 54, 883-895.

Yao, X., Yu, T., Zhao, B., Yu, Y., Liu, L., Ning, B., Wan, W., 2015. Climatological modeling of horizontal winds in the mesosphere and lower thermosphere over a mid-latitude station in China. Adv. Space Res. 56, 1354-1365.

Zhao, B., Wang, M., Wang, Y., Ren, Z., Yue, X., Zhu, J., Wan, W., Ning, B., Liu, J., Xiong, B., 2013. East-west differences in F-region electron density at mid-latitude: Evidence from the East Asian region. J. Geophys. Res. 118, 542-553, doi:10.1029/2012JA018235.

Zhang, D.H., Zhang, W., Li, Q., Shi, L.Q., Hao, Y.Q., Xiao, Z., 2010. Accuracy analysis of the GPS instrumental bias estimated from observations in middle and low latitudes. Annales Geophysicae, 28(8), 1571-1580.

Zhang, D.H., Xiao, Z., 2005. Study of ionospheric response to the 4B flare on 28 October 2003 using international GPS service network data. J. Geophys. Res. 110, A03307, doi:10.1029/2004JA010738.

Zhang, S.R., Chen, Z., Coster, A.J., Erickson, P.J., Foster, J.C., 2013. Ionospheric symmetry caused by geomagnetic declination over North America. J. Geophys. Res. 40, 5350-5354, doi:10.1002/2013GL057933.

Zhang, S.R., Coster, A.J., Holt, J.M., Foster, J.C., Erickson, P.J., 2012a. Ionospheric longitudinal variations at mid-latitudes: Incoherent Scatter Radar Observation at Millstone Hill. Sci. China Tech. Sci. doi:10.1007/s11431-012-4784-y. 
446 Zhang, S.R., Foster, J.C., Coster, A.J., Erickson, P.J., 2011. East-West Coast differences in total 447 electron content over the continental US. Geophys. Res. Lett. 38, L19101, 448 doi:10.1029/2011GL049116.

449 Zhang, S.R., Foster, J.C., Holt, J.M., Erickson, P.J., Coster, A.J., 2012b. Magnetic declination and 450 zonal wind effects on longitudinal differences of ionospheric electron density at mid-latitudes. J. 451 Geophys. Res. 117, A08329, doi:10.1029/2012JA017954. 

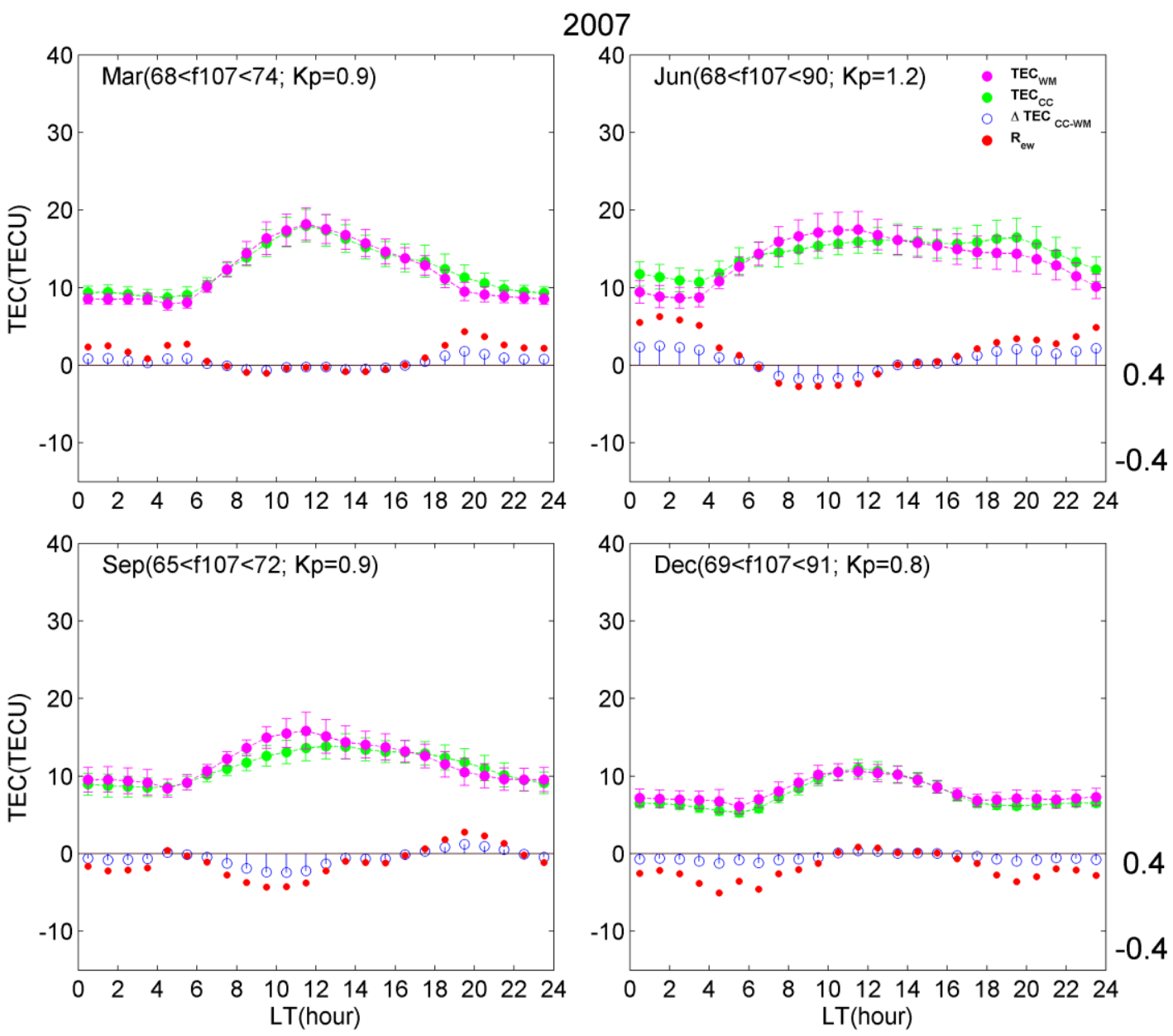

Fig. 1b. Same as Fig. 1a but for year 2007. 
526

527

528

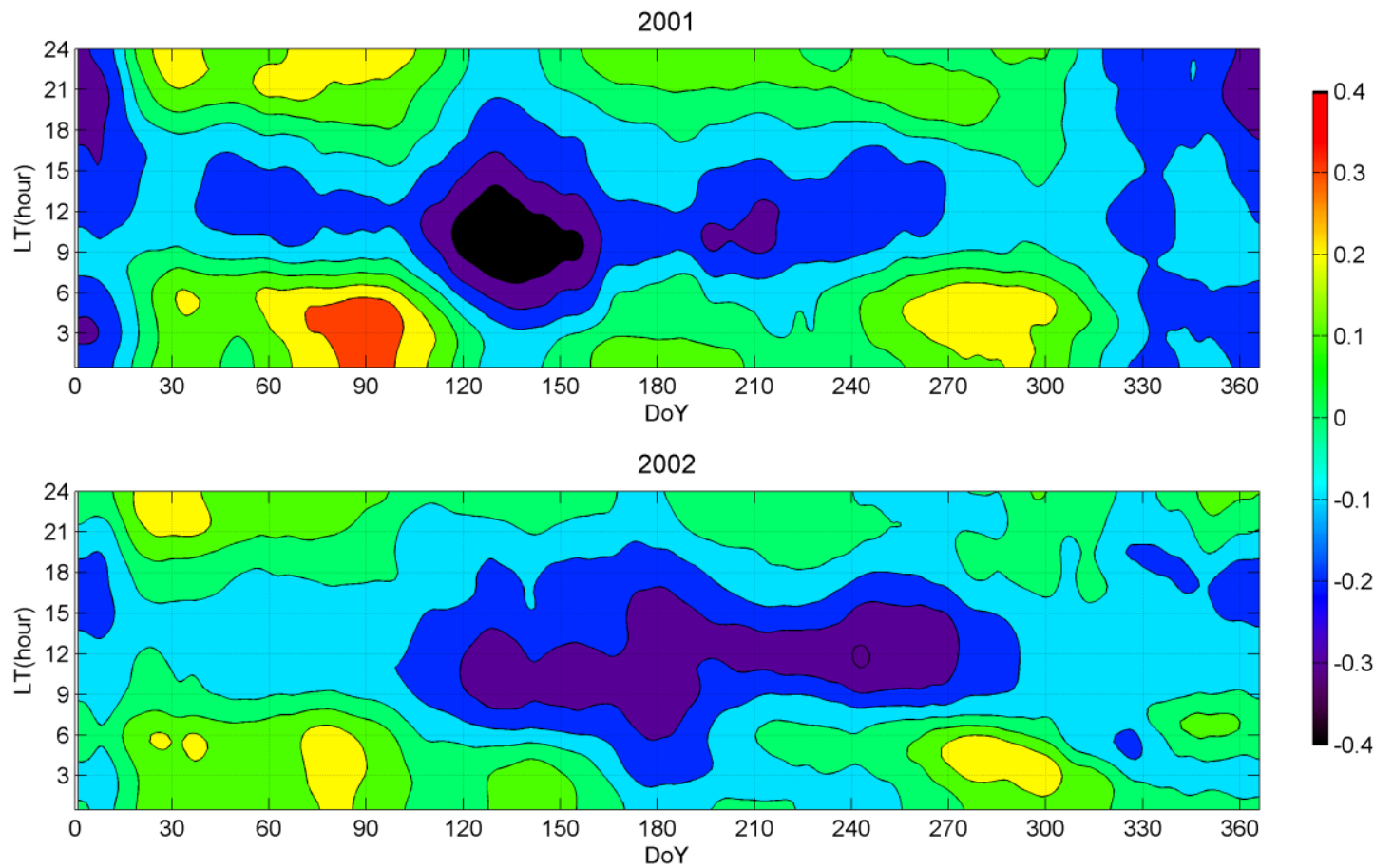

Fig. 2a. 31-day smooth mean $R_{\text {ew }}$ for TEC as a function of DoY vs. LT during high solar activity years of 2001-2002.

531

532

533

534

535

536

537

538

539

540

541

542

543

544

545

546

547

548

549 

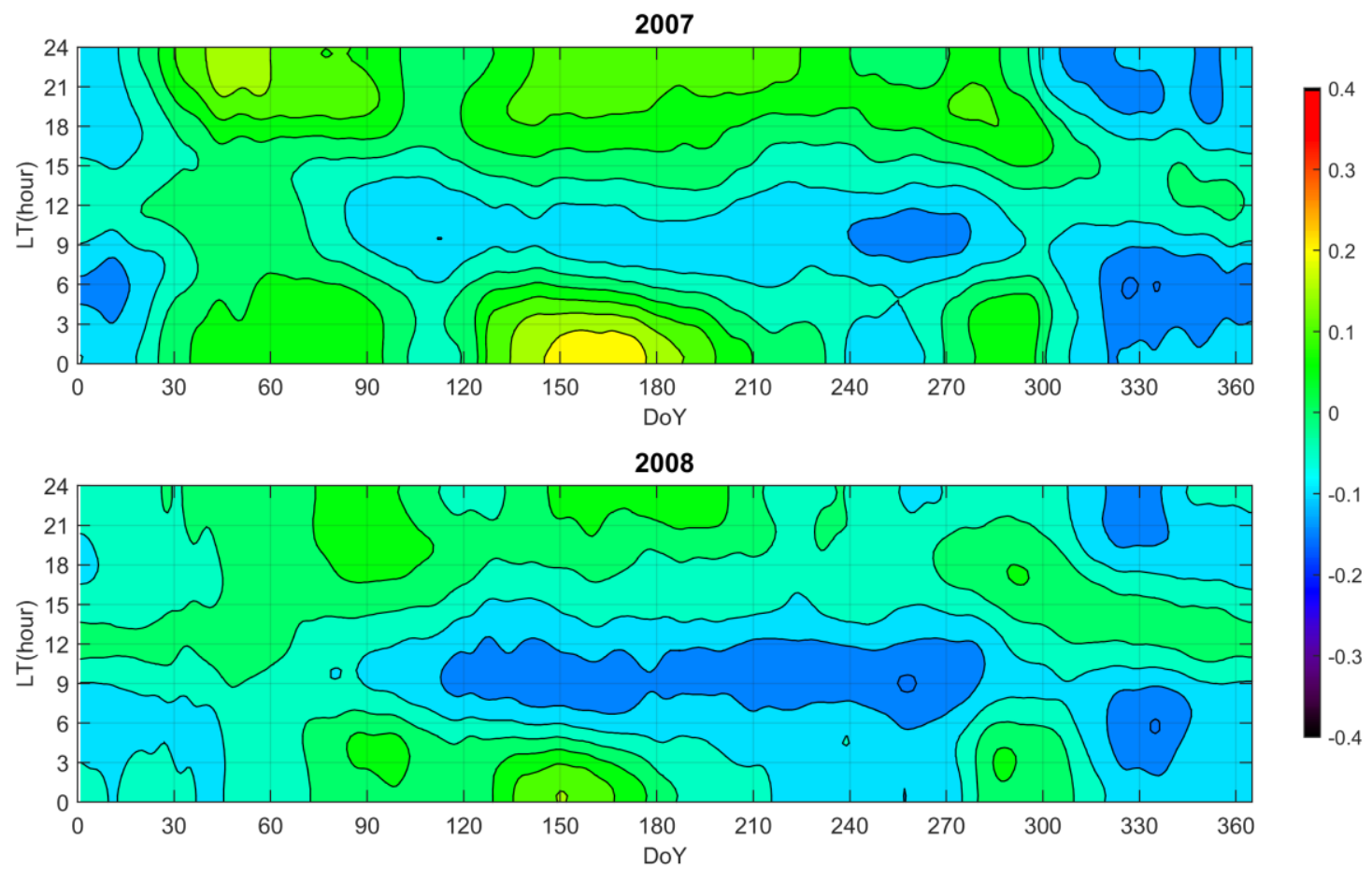

Fig. 2b. Same as Fig. 2a but during low solar activity years of 2007-2008.

553

554

555

556

557

558

559

560

561

562

563

564

565

566

567

568

569

570

571 

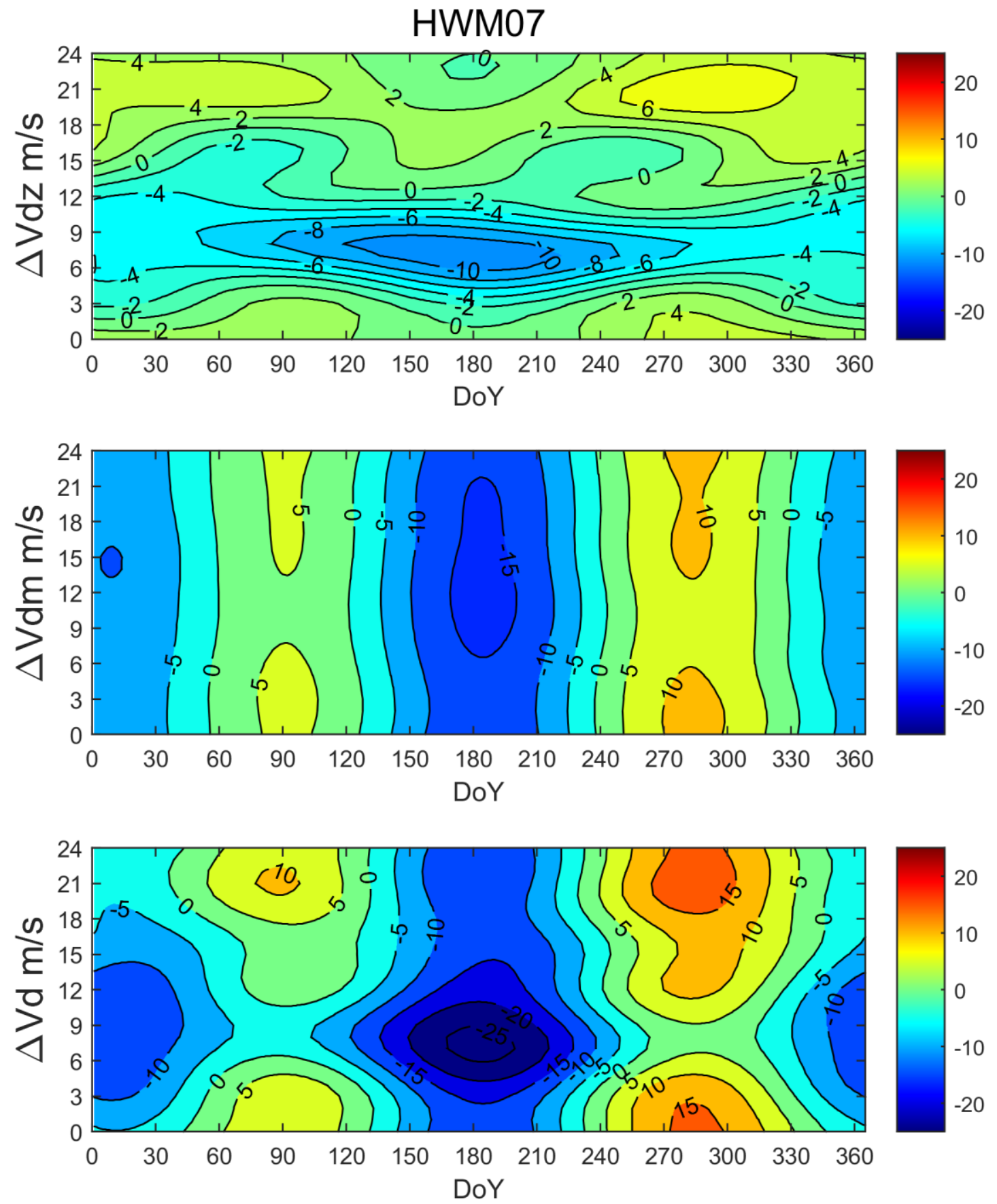

572

Fig. 3. The upper panel illustrates the DoY\&LT variation of $\Delta \mathrm{Vdz}$, difference in the vertical component of the field-aligned ion drift produced by the thermospheric zonal wind between Changchun and Urumqi. The middle panel presents the similar variation in $\Delta \mathrm{Vdm}$ produced by the meridional wind, and bottom panel shows their combined effect $(\Delta \mathrm{Vd})$. Thermospheric wind is derived from HWM07. 

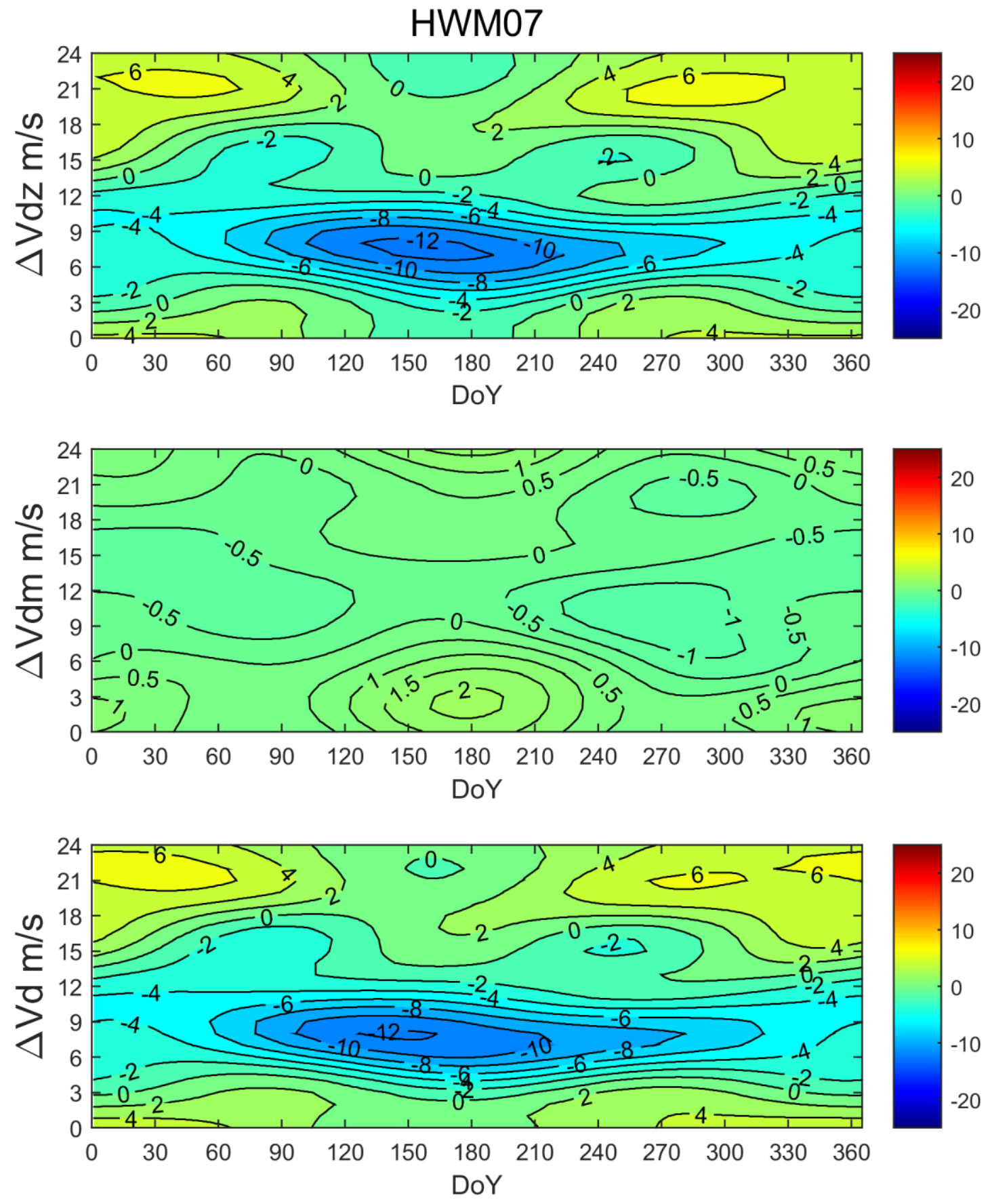

Fig. 4. Same as Fig. 3 but with the same diurnal thermospheric wind variation calculated at Changchun and Urumqi. Thermospheric wind is derived from HWM07. 